\title{
ACCESS TO CREDIT AND PHYSICAL CAPITAL STOCK: A STUDY OF NON-FARM HOUSEHOLD ENTERPRISES IN NIGERIA
}

\author{
Obed I. Ojonta* and Jonathan E. Ogbuabor** \\ * Corresponding author. Department of Economics, University of Nigeria, Nsukka. \\ Email: obed.ojonta@unn.edu.ng \\ ** Department of Economics, University of Nigeria, Nsukka. Email: jonathan.ogbuabor@unn.edu.ng
}

\begin{abstract}
This study investigated the influence of access to credit on the physical capital stock of non-farm household enterprises in Nigeria. The study used the binary logistic regression technique and Nigeria's 2018-19 General Household Survey data (Wave 4). We find that the influence of access to credit on the physical capital stock of nonfarm household enterprises in Nigeria is positive and significant. This implies that access to credit enhances the capacity of these enterprises to procure physical capital stock. Our results also indicate that expenditure on raw materials, profit, and years of operations are other key drivers of physical capital stock accumulation. Consequently, we conclude that there is a need for policies to enhance access to credit by non-farm household enterprises in Nigeria to strengthen their operations on a sustainable basis.
\end{abstract}

Keywords: Access to credit; Non-farm household enterprises; Physical capital stock; Binary logit model.

JEL Classifications: E51; R20; L11; C21.

Article history:

Received : November 10, 2020

Revised : January 01, 2021

Accepted : June 03, 2021

Available Online : December 31,2021

https://doi.org/10.21098/bemp.v24i4.1515 


\section{INTRODUCTION}

Non-farm Household Enterprises (NHEs) are owner-operated business enterprises that operate outside the farm sector or whose activities are outside primary agriculture, fishery, and forestry (Pasuhuk, 2018). Such enterprises share certain characteristics in common, namely: they operate mainly as informal enterprises; they utilize unpaid labour of household members rather than engage paid employees; they may or may not operate from fixed locations; they utilize personal relationships instead of contractual ones; and they operate under low level of organization (Kalla and Arora, 2011; Haggblade et al., 2010). Haggblade et al. (2010) also defined NHEs as "informal non-farm enterprises that are unincorporated and owned by households". Such enterprises operate as self-employed enterprises in non-agricultural sectors and may utilise only the labour of contributing family workers. Examples of such businesses in Nigeria include petty trading, shops like barber shops, tailoring shops, etc., food vendors, local restaurants, business centres, transport service providers (like taxi, 'keke' tricycle, and 'okada' motorcycle operators), construction, mining and quarrying, handicrafts, among others (Nagler and Naudé, 2017). It must be stressed that activities like processing and trading in agricultural products are non-farm activities, even if they are undertaken in the farm (Kalla and Arora, 2011).

The important roles of NHEs in terms of income generation, job creation, poverty reduction, diversification of means of livelihood, rural-urban migration reduction, and overall economic growth have been recognised by the extant literature. Haggblade et al. (2010) documented that $40 \%$ of households in low-income SubSaharan African economies rely on NHEs as their income source. Nagler and Naudé (2017) explained that, contrary to the expectations of the development economists of the 1960s and 70s, NHEs have continued to make increased contributions to household incomes and employment. Lam et al. (2019) demonstrated that NHEs play a considerable employment role among rural households, thereby reducing rural-urban migration and income inequalities. Nwosu et al. (2020) explained that NHEs supplement farm incomes, and thus reduce poverty among households. Nigeria's 2010/2011 General Household Survey, which was conducted on a nationally representative sample of 5,000 households, revealed that $77 \%$ and $62 \%$ of urban and rural households have someone operating at least one enterprise. This underlines the importance of these enterprises on livelihoods, especially on employment and income.

It has been found that some factors, such as poor physical infrastructure, high transaction costs, lack of electricity, high energy costs, low level of education, and lack of access to communication facilities, especially in rural areas, militate against the efficient and effective functioning of NHEs in developing economies (see e.g., Kalla and Arora, 2011; Rahji and Fakayode, 2009; Lam et al., 2019; Jimi et al., 2019). One important factor that could also hamper the performance of NHEs in Nigeria is the lack of access to credit. This is because access to credit can enable NHEs to acquire physical capital stock to enhance output quality, productivity, and efficiency of operations. In this context, access to credit occurs when an NHE obtains loan from either a bank or any other financial institution to satisfy its needs. Thus, access to credit can play important role in enhancing the performance of NHEs in Nigeria by increasing the capacity of such enterprises 
to acquire physical capital stock. This will then lead to an overall consumption improvement, employment generation, and poverty reduction (Pasuhuk, 2018).

Successive Nigerian governments have implemented several programmes aimed at solving the problem of access to credit by NHEs. For instance, the Community Banking Scheme was launched in 1991 to avail start-up credit to individuals, while the Micro, Small and Medium Enterprises Development Fund of the Central Bank of Nigeria was launched in 2013 to make credit available to smallholder enterprises like artisans and cottage industries (Ojonta et al., 2021). Other government schemes include Paylater, Renmoney, Page Financials, FINT Loan, Kwikmoney and Zedvance (Ojonta and Ogbuabor, 2021; Nwosu et al., 2018). Programmes implemented by the current government include: the Government Enterprise and Empowerment Programme, which was launched in 2016 to grant interest and collateral free credit to traders and artisans (Trader-moni), market women (Market-moni), and farmers (Farmer-moni); the disbursement of US\$1.3 billion in medium and long-term credit to business enterprises owned by youths and women since 2017 by the new Development Bank of Nigeria; the disbursement of over N400 billion in credit to micro, small, medium and large businesses since 2016 by the Bank of Industry; the US\$20 million Young Entrepreneurs Fund; and the N5 billion Artisanal Miners Fund created by the Federal Ministry of Mines and Solid Minerals Development. However, despite these government efforts, the challenge of access to credit by NHEs in Nigeria has persisted (Ojonta and Ogbuabor, 2021).

The foregoing discussion indicates that NHEs play an important role in income generation, job creation, and poverty reduction and that effort by successive Nigerian governments to make credit available to these enterprises have not yet yielded the desired result. Nevertheless, no study known to us has investigated how access to credit by these enterprises in Nigeria influences their physical capital stock accumulation. This leaves an important gap in the literature, which this study aims to fill. Consequently, the key questions asked in this study are: (a) how does access to credit impact on the physical capital stock of NHEs in Nigeria?; and (b) Are there other factors that significantly influence the physical capital stock of NHEs in Nigeria? Thus, the objectives of this study are twofold, namely: (i) to ascertain the influence of access to credit on the physical capital stock of NHEs in Nigeria; and (ii) to determine other factors that significantly influence the physical capital stock of NHEs in Nigeria. These objectives are important because identifying the factors influencing the physical capital stock of NHEs in Nigeria will enable policymakers to better address them, thereby enhancing the performance of these enterprises during the post Covid-19 era.

The remaining sections of this paper proceed as follows. The next section presents an overview of the extant literature from both theoretical and empirical perspectives, while Section III explains the data and the method of analysis employed in this study. The empirical results are reported and discussed in Section IV, while Section V concludes the paper. 


\section{LITERATURE REVIEW}

\section{A. Theoretical Literature}

Some theories underpin this study. These are credit rationing and constraint theory, financial intermediation theory, and imperfect information theory. According to the theory of credit rationing and constraint propounded by Stiglitz and Weiss (1981), individuals are willing to borrow provided the lenders are prepared to offer credit with low interest rates and securities. This implies that individuals are restricted from accessing credit based on the underlying conditions, such as collaterals and the interest rate. Empirical studies like Farida et al. (2016) are consistent with this theoretical perspective. The theory of financial intermediation advocated by Gurley and Shaw (1960) states that financial intermediaries take deposits and channel funds to firms as credit. The theory emphasizes the role of financial intermediaries in the allocation of funds in the economy (see (Claessens, 2006). Empirical studies, such as Ojo and Ayanwale (2019), are underpinned by this theoretical viewpoint.

Akerlof (1970) propounded the imperfect information theory to analyze the relationship between borrowers and lenders. The theory identified information asymmetry as a common characteristic of market interactions that could lead to adverse selection. The theory argued that borrowers often know more about their creditworthiness than lenders, and such asymmetric information could lead to exploitation on the part of the party that has better information. Thus, studies like Farida et al. (2016) emphasize the need for collateral in order to guarantee the repayment of credit to households.

\section{B. Empirical Literature}

Some studies have investigated the influence of credit access on firms within and outside Nigeria. Outside Nigeria, studies like Claessens (2006), Ojo and Ayanwale (2019), Farida et al. (2016), Pasuhuk (2018), estimated the influence of credit access on aggregate performance of enterprises. These studies generally established that access to credit impacts positively and significantly on the performance of enterprises. Some studies (e.g., Lam et al., 2019; Jimi et al., 2019) found that access to credit is an important driver of agricultural productivity, while others (Ojonta and Ogbuabor, 2021; Nwosu et al., 2018) showed that credit access enhances labour allocation patterns, total factor productivity, technology adoption, and business efficiency.

In Nigeria, studies (e.g., Nwosu and Orji, 2016; Nwosu et al., 2020) found that access to credit enhances agricultural yield and farm production of enterprises, while other studies (e.g., Adegbite, 2009; Rahji and Fakayode, 2009) found that credit access significantly improves agricultural productivity. Studies have also shown that access to credit impacts positively and significantly on the performance of enterprises (Nwosu and Orji, 2016; Ojonta and Ogbuabor, 2021). Overall, the different aspects of the empirical literature on the relationship between access to credit and household enterprises indicate that the impact of credit access on the physical capital stock of NHEs in Nigeria is yet to be investigated. Herein lies the contribution of this study to the literature. 


\section{DATA AND METHODOLOGY}

\section{A. Data}

This study used data from the Nigerian 2018-19 General Household Survey (Wave 4 ). This is a nationally representative survey of about 5,000 households across all the 36 states in Nigeria plus the Federal Capital Territory, based on a multi-stage stratified sampling design. However, only 244 households recorded data on access to credit by NHEs and these were included in this study. In order to avoid the problem of spurious regression, we adequately considered the issues of outliers and homogeneity by filtering out 18 outliers from the observations.

\section{B. Model Specification}

This study used a binary logistic regression model, which is a probability model used when the dependent variable is a binary variable, while the independent variables are either categorical or scale variables (Rahji and Fakayode, 2009). Since the physical capital stock of NHEs is a dichotomous indicator variable, we followed the modelling approach of Astari and Kismiantini, (2019). Let $\pi$ denote the physical capital stock of NHEs, while $X_{i}$ denotes the set of explanatory variables, which are either continuous or categorical variables. We assume that each category of physical capital stock is mutually exclusive, so that the binary logit model is coded as two outcomes. Thus, the binary logit model determines the probability that an enterprise $i$ has one of the $j$ mutually exclusive physical capital stock ( $0=$ No physical capital stock; while $1=$ with physical capital stock). Hence, following (Justino et al. (2008), this probability can be stated formally as:

$$
P\left(\pi_{i}=j\right)=1 / 1+e^{-(z)}
$$

Where $\mathrm{Z}=\beta_{0}+\beta_{1} X_{1}+\beta_{2} X_{2} \ldots+\beta_{p} X_{p^{\prime}} ; \beta_{0^{\prime}} \beta_{1^{\prime}} \beta_{2^{\prime}} \ldots, \beta_{p}$ are regression parameters; $X_{1^{\prime}}, X_{2^{\prime}} \ldots$ ,$X_{p}$ are explanatory variables, and $\pi$ is the probability that a NHE operates with physical capital stock.

Table 1.

\section{Definition of Variables}

This table shows the description of all the variables in this study. It also shows the a priori expectations for the independent variables based on the extant literature, where +ve denotes positive value while -ve denotes negative value. The data are drawn from the Nigerian 2018-19 General Household Survey (Wave 4).

\begin{tabular}{lccc}
\hline Variable Names & $\begin{array}{c}\text { Variables } \\
\text { Label }\end{array}$ & Coding & $\begin{array}{c}\text { A Priori } \\
\text { Expected Sign }\end{array}$ \\
\hline Physical Capital Stock $(Y)$ & STOCK & $1=$ yes; $0=$ No & Dependent Variable \\
Credit access $\left(X_{1}\right)$ & CREDIT & $1=y e s ; 2=$ No & +ve or - ve \\
Spending for raw materials $\left(X_{2}\right)$ & MATERIAL & $\begin{array}{c}1=y e s ; 2=\text { No } \\
1=0-9 \text { years of } \\
\text { operation; } 2=\text { more } \\
\text { than 9years of } \\
\text { Number of years }\left(X_{3}\right)\end{array}$ & -ve or -ve \\
& YEAR & +veration \\
Total profit $\left(X_{4}\right)$ & PROFIT & 1=yes, made profit; & 2=No profit \\
& & +ve or -ve \\
\hline
\end{tabular}


All the explanatory variables in Equation (1) are defined as shown in Table 1. These variables are also explained as follows:

- $X_{1}$ denotes CREDIT, which is a binary variable that takes a value of 1 if the enterprise got credit and a value of 2 if the enterprise did not get credit. Studies like Nagler and Naudé (2017) obtained a positive coefficient for this variable, while Aziz et al. (2017) obtained a negative coefficient. Hence, our a priori expectation is that the coefficient of this variable could be positive or negative.

- $X_{2}$ denotes MATERIAL, which is a binary variable that takes a value of 1 if there is spending on raw material and a value of 2 if there is no spending. Following Pasuhuk (2018), our a priori expectation for this variable is positive.

- $X_{3}$ denotes YEAR, which is a binary variable for which 1 implies that the NHE has been in operation between zero to 9years, while 2 implies that it has been in operation for more than 9 years. Adegbite (2009) obtained a positive coefficient for this variable, while Farida et al. (2016) obtained a negative coefficient. Thus, our a priori expectation is that the coffiecient for this variable could be positive or negative.

- $X_{4}$ denotes PROFIT, which is also a binary variable that takes a value of 1 if the enterprise made profit and a value of 2 if it made no profit. Following Ojo and Ayanwale, (2019) our a priori expectation for this variable is positive.

Table 2 shows the distribution of the NHEs by percentage of access to credit between the rural and urban sectors. The table also shows the distribution of NHEs according to those that procured physical capital stock and those that did not. This table is quite informative. For instance, we see that that did not procure physical capital stock have less access to credit than the ones that procured physical capital stock. This is true regardless of whether the NHE is located in the rural or urban areas. It also shows that credit access is still a serious challenge facing many NHEs, and that NHEs without credit access are mainly located in the rural areas.

Table 2.

\section{Distribution of NHEs by Percentage Share of Access to Credit}

This table shows the distribution of the Non-farm Household Enterprises (NHEs) in this study by percentage of access to credit between the rural and urban sectors. It also shows the distribution of these NHEs according to those that procured physical capital stock and those that did not.

\begin{tabular}{lcccccccc}
\hline & \multicolumn{3}{c}{ Access to Credit } & \multicolumn{4}{c}{ Non-access to Credit } \\
\hline & Rural & $\%$ & Urban & $\%$ & Rural & $\%$ & Urban & $\%$ \\
& Area & Share & Area & Share & Area & Share & Area & Share \\
\hline Physical capital & 27 & 93.1 & 30 & 93.75 & 88 & 83.02 & 66 & 85.71 \\
No-physical capital & 2 & 6.9 & 2 & 6.25 & 18 & 16.98 & 11 & 14.29 \\
Total & 29 & 100 & 32 & 100 & 106 & 100 & 77 & 100 \\
\hline
\end{tabular}

\section{EMPIRICAL RESULTS}

Table 3 presents the estimates of the binary logit model. The coefficient values and their corresponding $p$-values of the binary logit regression for the two categories of physical capital stock (i.e., "without physical capital stock" and "with physical capital stock") as the base outcome variable, are shown in Table 3. The results 
indicate that access to credit (CREDIT) has a positive coefficient of 1.512, which is statistically significant at $5 \%$ level. This means that the higher the access to credit, the higher will be the tendency for NHE to procure physical capital stock. The odds ratio of 4.53 to 1 in favour of an NHE procuring physical capital stock is consistent with this finding. This finding is consistent with Blanchflower and Evans (2004), who also found that access to credit by NHEs influences their procurement of physical capital stock. This finding is also consistent with studies like Aziz et al. (2017) and Nagler and Naude (2017). Thus, we find that access to credit is important to achieving investment in physical capital stock by NHEs in Nigeria.

The results in Table 3 also indicate that spending on raw materials (MATERIAL) by NHEs has a positive influence on the procurement of physical capital stock and that this influence is statistically significant at $5 \%$ level. This finding is in conformity with the studies by (Rahji and Fakayode, 2009). The odds ratio of 3.83 to 1 in favour of an NHE procuring physical capital stock is also consistent with this finding. At this point, our results have revealed that two factors, access to credit and spending on raw materials, are important to enhancing the performance of NHEs in Nigeria. These findings are interesting because these two factors would likely worsen in the aftermath of the ongoing Covid-19 pandemic. In Nigeria, Ojonta and Ogbuabor (2021) demonstrated that the pandemic has severely impacted on households and businesses. The evidence that has emerged from this study suggests that for NHEs to contribute towards growth and development in Nigeria on a sustainable basis in the post Covid-19 era, there is a need for government to frontally address the challenge of access to credit facing these enterprises.

The results in Table 3 further indicate that profit making, and years of operation also positively and significantly influence the procurement of physical capital stock by NHEs, which is in line with economic expectations. The findings are consistent with the odds ratios of 5.66 and 2.34 reported for these variables in favour of procuring physical capital stock. They are also consistent with studies like Haggblade et al. (2010), which also obtained positive coefficients for these variables.

Table 3.

\section{Results of Binary Logit Regression}

This table shows the results of the binary logit regression for this study. In this table, B denotes relative risk ratio value, which represents the estimated coefficients; S.E. denotes the robust standard errors; $\operatorname{Exp}(\mathbf{B})$ denotes the odd ratios computed as the exponential of the B Coefficient. ${ }^{* * *},{ }^{* *}$ and ${ }^{*}$ indicate significance at $1 \%, 5 \%$ and $10 \%$ levels, respectively.

\begin{tabular}{lcccc}
\hline \multicolumn{5}{c}{ Dependent Variable: } \\
\hline INDEsical Capital Stock \\
\hline INTERCEPT & B & S.E. & $p$-value & Exp(B) \\
CREDIT & -1.031 & 0.833 & 0.216 & 0.357 \\
MATERIAL & 1.512 & 0.61 & $(0.013)^{* *}$ & 4.534 \\
YEAR & 1.343 & 0.492 & $(0.006)^{* * *}$ & 3.83 \\
PROFIT & 0.849 & 0.438 & $(0.053)^{*}$ & 2.338 \\
\hline
\end{tabular}




\section{A. Diagnostic Checks}

The diagnostic tests in Table 4 indicate that the model is statistically significant at the $1 \%$ level. Though the pseudo $R$-squared $($ Cox \& Snell $=0.079$; Nagelkerke = 0.145 ) appear low, they are nonetheless in line with the values reported by Aziz et al. (2017) and Astari and Kismiantini, (2019). The percentage of correct prediction indicates that $86 \%$ can be accurately predicted by the model. These diagnostic checks indicate that our model is adequate for inference.

Table 4.

\section{Tests for Model Suitability}

This table shows the results of the diagnostic checks conducted to ensure that our model is adequate for inference. ${ }^{* * *}$ denotes significance at $1 \%$ level.

\begin{tabular}{lcc}
\hline Test Statistics & Value & Significance \\
\hline -2log-Likelihood & 173.259 & \\
Cox \& Snell R-square & 0.079 & \\
Nagelkerke $R$-square & 0.145 & 0.000 \\
Chi-square & $20.106^{* * *}$ & \\
Percentage correct prediction & 86.1 & \\
Number of Observations & 244 & \\
\hline
\end{tabular}

We also conducted classification tests as shown in Table 5. The results indicate that the Visible Error Rate (VER) and the overall Visible Correct Classification Rate (VCCR) were $6.96 \%$ and $93.03 \%$, respectively. These results indicate that the model performed well in terms of classification. These results are also consistent with Abdullah and Majid (2014) and Abdulqader (2017).

Table 5.

Final Classification Results for the Binary Logistic Model

This table shows the results of the classification tests conducted for the study. In this table, VER denotes Visible Error Rate, while VCCR denotes Visible Correct Classification Rate.

\begin{tabular}{lccc}
\hline Kind of Test & $\begin{array}{c}\text { No-Physical } \\
\text { Capital Stock }\end{array}$ & $\begin{array}{c}\text { Physical Capital } \\
\text { Stock }\end{array}$ & Total \\
\hline No-Physical Capital Stock & 1 & 32 & 33 \\
Physical Capital Stock & 2 & 209 & 211 \\
VER & & $13.93 \%$ & \\
VCCR & & $86.07 \%$ & \\
\hline
\end{tabular}

\section{CONCLUDING REMARKS}

Using a binary logistic regression model, we estimated the influence of access to credit on the physical capital stock of NHEs in Nigeria. The results indicate that access to credit, spending on raw materials, profit making, and years of operation are important drivers of the physical capital stock accumulation by NHEs in Nigeria. However, an important pattern observed in the data indicates that a greater percentage of the NHEs in both rural and urban areas are still lacking 
credit access. Thus, there is a need for policies that can address the issue of access to credit by NHEs in Nigeria. Such policies will enable the enterprises to easily enhance their physical capital stock on a sustainable basis, especially in the post Covid-19 era. Furthermore, the government's financial support for NHEs should be followed by adequate monitoring to ensure that such funds are not diverted to other uses. Going forward, it would be useful for researchers to extend this study by further conducting analysis on the aggregate performance of household enterprises in Nigeria and other countries, particularly in the post Covid-19 era. There is also a need for researchers to analyse how the pandemic has impacted on access to credit and acquisition of physical capital stocks by NHEs in Nigeria. Such studies will help to strengthen policy efforts towards solving the problems of credit access and acquisition of physical capital stock by NHEs in Nigeria.

\section{REFERENCES}

Adegbite, D. A. (2009). Repayment Performance of Beneficiairies of Ogun State Agricultural and Multipurpose Credit Agency (OSAMCA) in Ogun State, (2004-2007). American-Eurasian Journal of Sustainable Agriculture, 3, 117-125.

Akerlof, G. (1970). The Market for Lemons: Quality, Uncertainty and the Market Mechanism. Quarterly Journal of Economics, 84, 488-500.

Astari, D., \& Kismiantini. (2019). Analysis of Factors Affecting the Health Insurance Ownership with Binary Logistic Regression Model. Journal of Physics: Conference Series. https://doi.org/10.1088/1742-6596/1320/1/012011

Aziz, B., Wasim, S., \& Iqbal, Z. (2017). Consumption Behavior and Household Economies of Scale an Analysis of Variations Across Rural-urban Regions of Pakistan. International Journal of Health and Medicine, 2, 6-11. https://doi.org/10.24178/ijhm.2017.2.3.06

Claessens, S. (2006). Access to Financial Services: A Review of the Issues and Public Policy Objectives. The World Bank Research Observer, 21, 207-240. https://doi.org/DOI: 10.1093/wbro/lk1004

Farida, F., Siregar, H., Nuryartono, N., \& KP, E. (2016). Determinant of Microcredit Repayment. Buletin Ekonomi Moneter dan Perbankan, 19, 57-80. https://doi.org/10.21098/bemp.v19i1.600

Gurley, J., \& Shaw, E. (1960). Money in a Theory of Finance, Brookings.

Haggblade, S., Hazell, P., \& Reardon, T. (2010). The Rural Non-farm Economy: Prospects for Growth and Poverty Reduction. World Development, 38, 14291441.

Jimi, N. A., Nikolov, P., Malek, M. A., \& Kumbhakar, S. (2019). Effects of Access to Credit on Productivity : Separating Technological Changes from Changes in Technical Efficiency. Journal of Productivity Analysis, 52, 37-55. https://doi.org/10.1007/s11123-019-00555-8

Justino, P., Litchfield, J., \& Pham, H. T. (2008). Poverty Dynamics During Trade Reform: Evidence from Rural Vietnam. Review of Income and Wealth, 54, 166192.

Kalla, S. M., \& Arora, A. P. (2011). Impulse Buying: A Literature Review. Global Business Review, 12, 145-157. 
Lam, B. T., Hop, H. T. M., Burny, P., Dogot, T., Cuong, T. H., \& Lebailly, P. (2019). Impacts of Credit Access on Agricultural Production and Rural Household's Welfares in Northern Mountains of Vietnam. Asian Social Science, 15, 119-133. https://doi.org/10.5539/ass.v15n7p119

Nagler, P., \& Naudé, W. (2017). Non-farm Entrepreneurship in Rural Sub-Saharan Africa: New Empirical Evidence. Food Policy, 67, 175-191.

Nwosu, E. O., Ojonta, O., \& Orji, A. (2018). Household Consumption Expenditure and Inequality: Evidence from Nigerian Data". International Journal of Development Issues, 17, 266-287. https://doi.org/10.1108/IJDI-06-2017-0113

Nwosu, E. O., \& Orji, A. (2016). Access to Formal Credit and Enterprises Performance in Nigeria: A Gender Perspective. Argumenta Oeconomica, 1, $193-$ 223. https://doi.org/10.15611/aoe.2016.1.08

Nwosu, E., Orji, A., Urama, N. E., Emecheta, C., Chukwuma, O. Q., \& Chukwuma, J. N. (2020). Social Capital, Credit Access and Household Nonfarm Enterprises in Nigeria: A new Empirical Evidence. Forum for Social Economics. https://doi.org/10.1080/07360932.2020.1825983

Ojo, M. P., \& Ayanwale, A. B. (2019). Estimating Farm-level Financing Gap: A Technical Efficiency Approch. Agricultural Finance Review, 79, 74-191.

Ojonta, O. I., Obodoechi, D. N., \& Ugwu, P. N. (2021). Start-up Capital Source and Credit Access Participation of Household Nonfarm Enterprises in Nigeria: Evidence from Logistic Regression Model. Managing Global Transitions, 19, 249-267. https://doi.org/10.26493/1854-6935.19.249-267

Ojonta, O., \& Ogbuabor, J. (2021). Credit Access and the Performance of Non-farm Household Enterprises: Evidence from Nigerian Data. International Journal of Sustainable Economy, 13, 72-86. https://doi.org/10.1504/IJSE.2021.113318

Pasuhuk, P. M. (2018). Contribution of Financial Depth and Financial Access to Poverty Reduction in Indonesia. Bulletin of Monetary Economics and Banking, 21, 95-122. https://doi.org/10.21098/bemp.v21i1.89

Rahji, M. A. Y., \& Fakayode, S. A. (2009). Multinomial Logit Analysis of Agricultural Credit Rationing by Commercial Banks in Nigeria. International Research Journal of Finance and Economics, 24. Retrieved from eurojournals.com/finance.htm

Stiglitz, J., \& Weiss, A. (1981). Credit Rationing in Markets with Imperfect Information. The American Economic Review, 71, 393-410. 